\title{
Aplikasi Nilai Mahasiswa Fakultas Teknik Universitas Muhammadiyah Bengkulu Berbasis Web
}

\author{
Arius Satoni Kurniawansyah ${ }^{1}$, Rizka Tri Alinse ${ }^{2}$, Rina Julita ${ }^{3}$ \\ 1,2,3 Teknik Informatika, Universitas Dehasen Bengkulu \\ Email : ariussatoni@yahoo.co.id
}

\begin{abstract}
Information obtained from the internet varies from the information required user (User). One of the information we get is the number of educational sites ranging from high school level up to the level of the Academic Campus. For Educational Institutions, an Information System is needed for media information in running Vision and Mission Agency. In this study built an Application Value Faculty of Engineering, University of Muhammadiyah Bengkulu Web Based. Information services are limited in the information value of student Faculty of Engineering Informatics Prodi UMB. The study's goal was to find out how to make the Application Value of web-based student in the Faculty of Engineering UMB, improve service quality information of value to students in the Faculty of Engineering UMB and UMB Faculty facilitate student access to information value. The benefit of this research is to produce a web-based application Students value the latest in the Faculty of Engineering and Faculty of Engineering UMB UMB can get value quickly, easily, and efficiently. Score application development methodology Faculty of Engineering, University of Muhammadiyah Bengkulu is Web-based data analysis, software requirements specification, functional requirements design, and implementation. The software used is Macromedia Dreamweaver 8 with PHP programming language and the MySQL database to store its data. The results of this study in the form of an Application Value Faculty of Engineering, University of Muhammadiyah Bengkulu Web Based. Web-Based Application is an application that manages data into information and information is uploaded via the website, so the information accessed easily get the information they needed.
\end{abstract}

Keywords: User, Website

Intisari-Informasi yang diperoleh dari internet itu bermacam-macam tergantung dari informasi yang dibutuhkan user (Pemakai). Salah satu informasi yang kita peroleh adalah banyaknya situs-situs pendidikan mulai dari tingkatan SMA sampai dengan tingkat Kampus Akademik. Bagi Lembaga Pendidikan, sebuah Sistem Informasi sangat dibutuhkan untuk media informasi dalam menjalankan Visi dan Misi Lembaga. Pada penelitian ini dibangun sebuah Aplikasi Nilai Mahasiswa Fakultas Teknik Universitas Muhammadiyah Bengkulu Berbasis Web. Pelayanan informasinya dibatasi pada informasi nilai mahasiwa Fakultas Teknik Prodi Teknik Informatika UMB. Tujuan Penelitian adalah untuk mengetahui bagaimana cara membuat Aplikasi Nilai Mahasiswa yang berbasis web di Fakultas Teknik UMB, meningkatkan kualitas pelayanan informasi nilai bagi mahasiswa di Fakultas Teknik UMB, dan memudahkan mahasiswa Fakultas Teknik UMB dalam mengakses informasi nilai. Adapun manfaat dari penelitian ini adalah dapat menghasilkan suatu Aplikasi Nilai Mahasiswa berbasis web yang terbaru di Fakultas Teknik UMB dan Mahasiswa Fakultas Teknik UMB dapat memperoleh informasi nilai secara cepat, mudah, dan efisien. Metodelogi pengembangan Aplikasi Nilai Mahasiswa Fakultas Teknik Universitas Muhammadiyah Bengkulu Berbasis Web ini adalah analisa data, spesifikasi kebutuhan perangkat lunak, perancangan kebutuhan fungsional, dan implementasi. Perangkat lunak yang digunakan adalah Macromedia DreamWeaver 8 dengan bahasa pemrograman PHP dan MySQL untuk menyimpan basis datanya. Hasil penelitian ini berupa sebuah Aplikasi Nilai Mahasiswa Fakultas Teknik Universitas Muhammadiyah Bengkulu Berbasis Web. Aplikasi yang Berbasis Web adalah sebuah aplikasi yang mengelola data menjadi informasi dan informasi tersebut diupload melalui Website, sehingga para pengakses informasi dengan mudah mendapatkan informasi yang diperlukannya.

Kata kunci : User, Website

\section{PENDAHULUAN}

Kemajuan Teknologi Informasi di era globalisasi saat ini sangat berkembang pesat dengan adanya internet, maka orang dapat dengan cepat memperoleh informasi sesuai dengan kebutuh- 
annya. Internet sebagai dunia maya merupakan suatu bentuk jaringan yang memungkinkan seseorang mengakses informasi dari server yang terletak di tempat lain, dimana terkadang bisa terletak di sebelahan bumi atau di ruangan sebelah pengakses informasi. Informasi ini diakses dengan sebuah program aplikasi yang biasa kita sebut dengan browser.

Informasi yang diperoleh dari internet itu bermacam-macam tergantung dari informasi yang dibutuhkan user (Pemakai). Salah satu informasi yang kita peroleh adalah banyaknya situs-situs pendidikan mulai dari tingkatan SMA sampai dengan tingkat Kampus Akademik. Bagi Lembaga Pendidikan, sebuah Sistem Informasi sangat dibutuhkan untuk media informasi dalam menjalankan Visi dan Misi Lembaga.

Fakultas Teknik UMB belum memiliki Sistem Informasi Nilai Mahasiswa yang berbasis web. Sistem informasi Nilai Mahasiswa yang ada di Fakultas Teknik UMB masih sederhana yaitu menggunakan blog dan facebook. Informasinya belum terorganisir dengan baik sehingga menyulitkan mahasiswa Fakultas Teknik dalam mengakses informasi nilai yang diperlukan. Oleh karena itu Mahasiswa di Fakultas Teknik sangat memerlukan suatu Sistem Informasi Nilai Mahasiswa yang lebih baik lagi.

Berdasarkan hal diatas, maka penulis mengambil judul "Aplikasi Nilai Mahasiswa Fakultas Teknik Universitas Muhammadiyah Bengkulu Berbasis Web".

\section{LANDASAN TEORI}

\section{A. Software}

Nama lain dari Software adalah perangkat lunak. Karena disebut juga sebagai perangkat lunak, maka sifatnya pun berbeda dengan hardware atau perangkat keras, jika perangkat keras adalah komponen yang nyata yang dapat dilihat dan disentuh oleh secara langsung manusia, maka software atau Perangkat lunak tidak dapat disen- tuh dan dilihat secara fisik, software memang tidak tampak secara fisik dan tidak berwujud benda namun bisa untuk dioperasikan.

Pengertian Software komputer adalah sekumpulan data elektronik yang disimpan dan diatur oleh komputer, data elektronik yang disimpan oleh komputer itu dapat berupa program atau instruksi yang akan menjalankan suatu perintah. Melalui sofware atau perangkat lunak inilah suatu komputer dapat menjalankan suatu perintah.

Perangkat lunak komputer berdasarkan distribusinya dibedakan menjadi beberapa macam, yaitu software berbayar, software gratis atau free ( Freeware, free software, shareware, adware). ( belajar-komputer-mu.com/pengertian-softwareperangkat-lunak-komputer/, $2012: 1$ ).

\section{B. Hardware}

Perangkat Keras (Hardware) dalam komputer adalah perangkat yang terdiri dari alat-alat yang dapat difungsikan untuk menjalankan atau mendukung suatu operasi tertentu yang dipasang dalam sebuah Komputer.

Masing-masing perangkat keras mempunyai fungsi yang berbeda dalam penggunaannya sesuai kebutuhan pemakai, pada umumnya perangkat keras suatu sistem komputer terdiri dari :

\section{1) Central Processing Unit (CPU)}

Terdiri Aritmatic Logical Unit, yang melaksanakan proses penghitungan dan Control Unit, yang berfungsi mengontrol seluruh jaringan kerja peralatan komputer.

2) Storage berfungsi menyimpan data.

3) Input Device dan Output Device berfungsi sebagai unit masukan dan keluaran.

Sehingga dapat disimpulkan Hardware adalah suatu benda yang dapat dilihat dan dipegang fisiknya, yang dapat menerima dan mengolah data menjadi Informasi yang dibutuhkan secara cepat dan tepat. (Setiawan, 2005:30).

\section{XАMPP}

$X A M P P$ adalah perangkat lunak bebas, yang 
mendukung banyak sistem operasi, merupakan kompilasi dari beberapa program.

Fungsinya adalah sebagai server yang berdiri sendiri (localhost), yang terdiri atas program Apache HTTP Server, MySQL database, dan penerjemah bahasa yang ditulis dengan bahasa pemrograman PHP dan Perl. Nama XAMPP merupakan singkatan dari $\mathrm{X}$ (empat sistem operasi apapun), Apache, MySQL, PHP dan Perl. Program ini tersedia dalam GNU General Public License dan bebas, merupakan web server yang mudah digunakan yang dapat melayani tampilan halaman web yang dinamis. Untuk mendapatkanya dapat mendownload langsung dari web resminya. (wikipedia.org/wiki/XAMPP, 2012: 1)

\section{Macromedia Dreamweaver 8}

Macromedia DreamWeaver 8 adalah aplikasi yang menonjolkan editing secara visual dalam pembuatan halaman web tanpa harus menulis sebaris kode. DreamWeaver menyediakan suatu persandian penuh yaitu Code Editing Tool (seperti code coloring, tag completation, coding toolbar, dan code collapse) dan Language Reference (seperti Cascading Style Shets (CSS), Java Script, Cold Fusion Markup language (CMFL) dan bahasa lain. (H. Taufik H, 2007:10).

Macromedia dreamweaver adalah suatu aplikasi komputer yang di gunakan untuk membuat iklan atau pun membuat agen promosi secara online di internet yang juga bisa saling terhubung dengan link jejaring social seperti facebook,twitter,blogger,yahoo dan lainnya. (Dersy, 2012 :1).

\section{E. Internet}

Internet berasal dari kata Interconection Network yang mempunyai arti hubungan berbagai komputer dengan berbagai tipe yang membentuk sistem jaringan yang mencakup seluruh dunia (Jaringan Komputer Global) dengan melalui telekomunikasi seperti telepon. Setiap komputer dan jaringan terhubung secara langsung maupun tidak langsung ke beberapa jalur utama dan dibedakan dengan satu dan yang lainnya menggunakan unique name yang biasa disebut dengan IP 32 bit, contoh : 202.155.230.

Komputer dan jaringan dengan berbagai platform yang mempunyai perbedaan dan cirri khas masing-masing (Unix, Linux, Windows, Max, dan lain-lain) bertukar informasi dengan sebuah protokol standar yang dikenal dengan nama TCP/ IP (Transmission Control Protocol/Internet Protocol). TCP/IP tersusun atas empat layer (Network Acces, Host to, Host Transport, dan Aplication) yang masing-masing memiliki Protokol sendirisendiri.

Internet merupakan jaringan komputer yang dibentuk oleh Departemen Pertahanan Amerika Serikat di tahun 1969, melalui proyek ARPA yang disebut ARPANET (Advanced Research Project Agency Network), di mana mereka mendemonstrasikan bagaimana dengan hardware dan software komputer yang berbasis UNIX, kita bisa melakukan komunikasi dalam jarak yang tidak terhingga melalui saluran telepon.

\section{METODOLOGI PENELITIAN}

\section{A. Tempat dan Waktu}

Penelitian ini dilakukan di Fakultas Teknik Universitas Muhammadiyah Bengkulu yang beralamat di Jln Kampung Bali Kota Bengkulu, yang dimulai pada tanggal 3 Januari sampai 6 Febuari 2013.

\section{B. Metode Pengumpulan Data}

Untuk mendapatkan data yang diperlukan penulis menggunakan metode sebagai berikut :

1) Observasi

Mengadakan pengamatan langsung ke lapangan untuk mengumpulkan data primer.

2) Wawancara

Penyusunan mengadakan Tanya jawab dengan karyawan Lembaga Perguruan Tinggi tersebut dan pihak lain yang membantu dalam pembuatan laporan ini. 


\section{3) Study Pustaka}

Yaitu dengan cara membaca dan mempelajari buku-buku, yang berhubungan dengan permasalahan penelitian, diperoleh dari perpustakaan, tempat penelitian dan tempat lainnya yang ada hubungannya dengan judul yang penulis buat.

\section{PEMBAHASAN}

\section{A. Tampilan Menu Login}

Menu Login adalah menu untuk login bagi Admin atau pengelola Website Sistem Informasi Nilai Mahasiswa Fakultas Teknik Universitas Muhammadiyah Bengkulu. Adapun Tampilannya sebagai berikut :

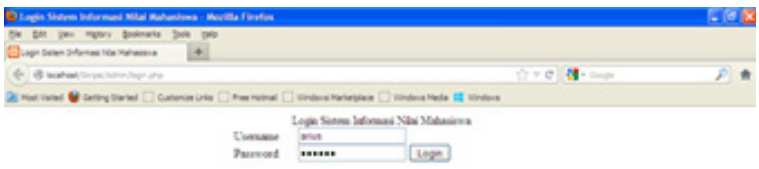

\section{B. Tampilan Menu Utama}

Tampilan Menu Utama adalah tampilan awal pada saat mahasiswa membuka situs Sistem Informasi Nilai Mahasiswa Fakultas Teknik Universitas Muhammadiyah Bengkulu. Adapun tampilannya sebagai berikut :

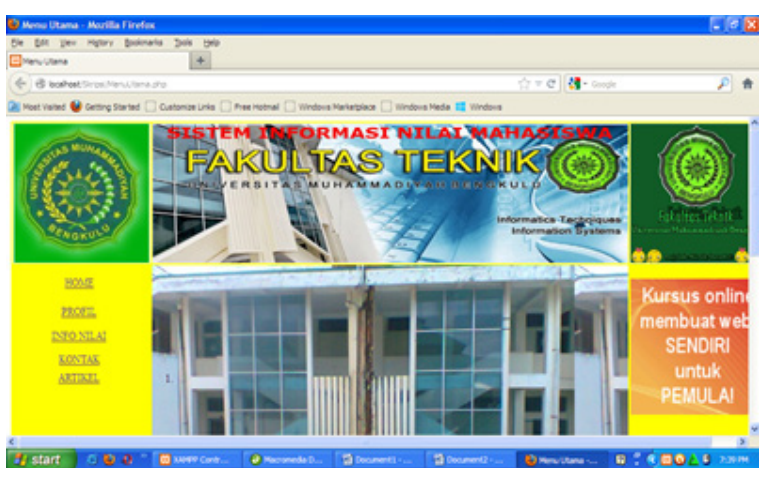

Fungsi coding <input type="text" name $=$ "username" id="username" $\mid>$ adalah untuk menyediakan tempat menginputkan nama user atau admin yang akan mengelola Database nilai mahasiswa.
Fungsi coding $<$ td height=" 44 " $><$ div alig$\mathrm{n}=$ "center" $><\mathrm{a}$ href="MenuHome.php" target $=$ " parent" $>$ HOME $</ a><$ href="Menu Home.html" target $=$ " parent" $></ \mathrm{a}></$ div $></$ td $>$ adalah untuk menambahkan Sub Menu pada Menu Utama.

\section{Tampilan Menu Home}

Tampilan Menu Home adalah tampilan yang berisi kata pengantar dari Website Sistem Informasi Nilai Mahasiswa Fakultas Teknik Universitas Muhammadiyah Bengkulu. Adapun tampilannya sebagai berikut :

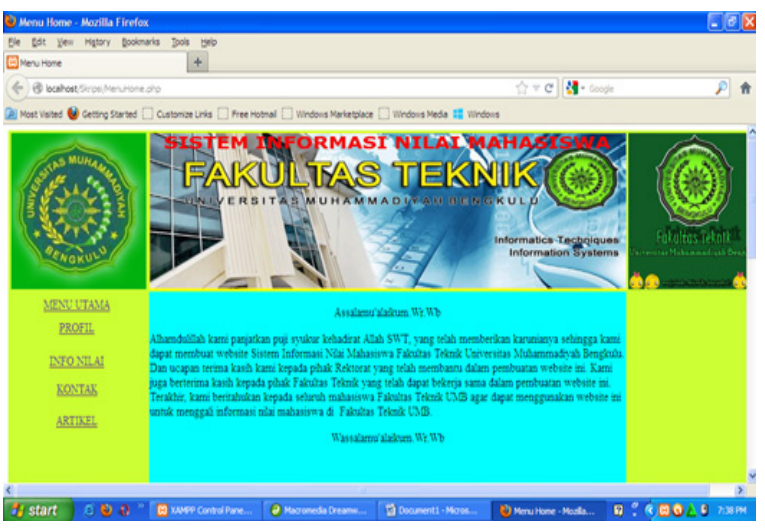

Fungsi coding <meta http-equiv="ContentType" content="text/html; charset=iso-8859-1" / $><$ title $>$ Menu Home $<$ /title $><$ style type="text $/$ css" $><$ ! — adalah untuk memberikan nama pada Menu Home.

\section{Tampilan Menu Profil}

Tampilan Menu Profil adalah tampilan yang berisi Profil dari Fakultas Teknik Universitas Muhammadiyah Bengkulu. Adapun Tampilannya sebagai berikut :

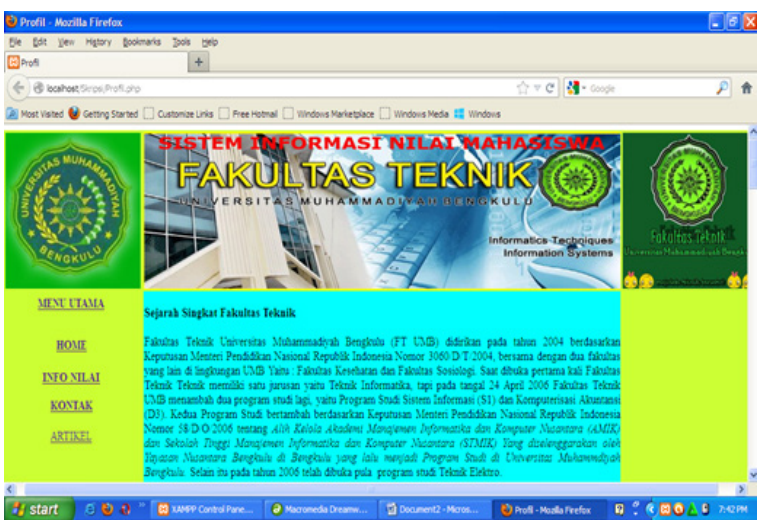


Fungsi coding $<$ head $><$ meta http=equiv"Content-Type" content $=$ "text $/ \mathrm{html}$; charset $=\mathrm{i}$ so-8859-1" $><<$ title $>$ Profil $</$ title $><$ style ty$\mathrm{pe}=$ "text/css" $><!$ - adalah untuk memberikan nama pada menu Profil.

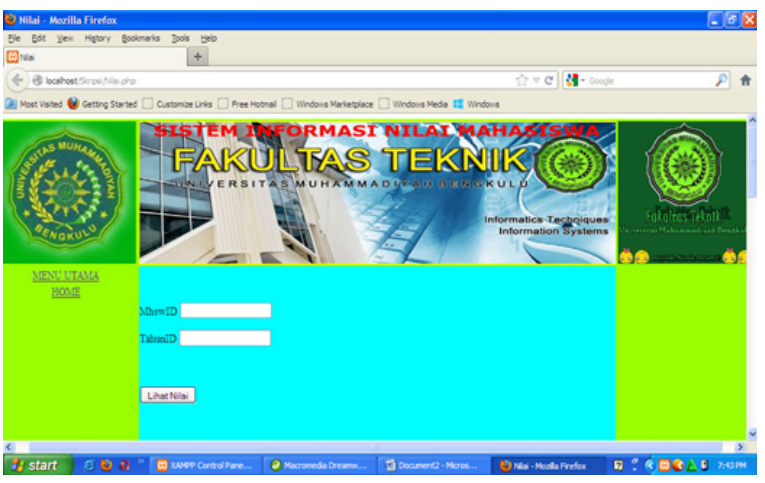

Fungsi coding $<$ ?php mysql_select_db $(\$ d a-$ tabase_Nilai, \$Nilai); \$query_Recordset1 = "SELECT * FROM krsmhsw"; adalah untuk mengkoneksikan database nilai mahasiswa ke Sistem Informasi Nilai Mahasiswa yang didesain di Macromedia DreamWeaver 8 dengan bahasa PHP.

\section{F. Pengujian Sistem}

Pengujian dimaksudkan untuk menguji apakah system yang telah dibuat akan menemui kendala-kendala atau perbaikan-perbaikan sehingga pengembangan sistemnya akan sesuai dengan harapan dan keinginan ditempat penulis melakukan penelitian. Pengujian system meliputi On going Evaluation dan Alpha Testing.

On going Evaluation : melakukan pengujian system pada http://localhost/phpmyadmin/MenuUtama.php namun tetap sesuai dengan standar operasional pada sebuah system informasi. Hal ini dimaksudkan untuk menilai apakah system yang penulis bangun sudah beroparasi dengan maksimal sesuai dengan harapan sebelum di upload kedalam sebuah web hosting.

Alpa Testing: memperlihatkan hasil system yang telah dibangun kepada pihak-pihak yang berwenang dalam hal ini pihak Fakultas Teknik Universitas Muhammadiyah Bengkulu serta dengan orang-orang Ahli dibidangnya yang ada di Fakultas Teknik Universitas Muhammadiyah Bengkulu.

\section{G. Hasil Pengujian}

Hasil Pengujian yang penulis dapatkan ini adalah hasil dari para responden yang telah mengisi formulir kuisioner terhadap pembuatan Aplikasi Nilai Mahasiswa Fakultas Teknik UMB berbasis Web, adapun responden yang ikut serta dalam pengisian formulir adalah para mahasiswa dan dosen Fakultas Teknik Universitas Muhammadiyah Bengkulu.

Komposisi kuisioner yang penulis lakukan pada penelitian ini adalah dengan melibatkan 8 responden dengan 5 buah pertanyaan. Hasil pengujian menggunakan kusioner menunjukkan hasil sebagai berikut.

1. Aplikasi Nilai Mahasiswa Fakultas Teknik UMB berbasis Web yang dibangun sangat diperlukan oleh civitas akademika Fakultas Teknik UMB

2. Aplikasi Nilai Mahasiswa Fakultas Teknik UMB berbasis Web yang dibangun sangat mudah dioperasikan oleh user

3. Aplikasi Nilai Mahasiswa Fakultas Teknik UMB berbasis Web yang penulis bangun dirasa sangat mudah ketika user menginput data

4. Aplikasi Nilai Mahasiswa Fakultas Teknik UMB berbasis Web yang penulis bangun ini telah sesuai dengan harapan para mahasiswa dan dosen Fakultas Teknik Universitas Muhammadiyah Bengkulu

5. Aplikasi Nilai Mahasiswa Fakultas Teknik UMB berbasis Web yang penulis bangun sangat bermanfaat karena sangat membantu dalam penyampaian informasi bagi civitas akademika Fakultas Teknik UMB

\section{PENUTUP}

\section{A. Kesimpulan}

Setelah menyelesaikan Aplikasi Nilai Mahasiswa Fakultas Teknik Universitas Muhammadiyah Bengkulu Berbasis Web, penulis menarik kesimpulan sebagai berikut : 
1. Aplikasi yang Berbasis Web adalah sebuah aplikasi yang mengelola data menjadi informasi dan informasi tersebut diupload melalui Website, sehingga para pengakses informasi dengan mudah mendapatkan informasi yang diperlukannya.

2. Sebuah Lembaga Pendidikan sangat memerlukan sebuah Aplikasi yang mengenai Sistem Informasi, khususnya informasi mengenai nilai anak didiknya. Dengan adanya Sistem Informasi yang baik maka sebuah Lembaga Pendidikan dapat menjalankan Visi Misinya dengan sukses.

\section{B. Saran}

Penulis ingin memberikan beberapa saran yang mungkin dapat membantu dalam pengembangan Aplikasi Sistem Informasi Nilai Mahasiswa Fakultas Teknik Universitas Muhammadiyah Bengkulu Berbasis Web ini, yaitu :

1. Aplikasi Nilai Mahasiswa Fakultas Teknik Universitas Muhammadiyah Bengkulu Berbasis Web ini dapat dikembangkan dengan menambahkan Aplikasi Website yang bisa menarik pengunjung sesuai dengan perkembangan teknologi.

2. Aplikasi Nilai Mahasiswa Fakultas Teknik Universitas Muhammadiyah Bengkulu Berbasis Web ini dapat dikembangkan menjadi Website bernilai ekonomi dengan memasang iklan produk perusahaan di beberapa bagian pada tampilan Website.

\section{DAFTAR PUSTAKA}

http://id.wikipedia.org/wiki/XAMPP

(Diakses pada tanggal 15 Desember 2012)

belajar-komputer-mu.com/pengertian-softwareperangkat-lunak-komputer/ (Diakses pada tanggal 12 Desember 2012)

http://dersyajha.blogspot.com/2012/02/belajarmacromedia-dreamweaver-8.html (Diakses pada tanggal 12 Desember 2012)

lecture.eepis-its.edu/ hero/datahero/kuliah/RPL/ DFD-1.pdf (Diakses pada tanggal 12 Desember 2012)

Setiawan, Agung. 2005. Pengantar Sistem Komputer, Informatika Bandung

Sidik, Betha. 2007. Pemrograman Web dengan HTML, Informatika Bandung

Kadir, Abdul. 2008. Belajar Database menggunakan MySQL, Andi Yogyakarta 